\title{
O imaginário de leitura no Ensino Fundamental II: o que os alunos dizem?
}

Ana Paula Kuchla*

Luciana Fracasse ${ }^{* *}$

\begin{abstract}
Resumo:Este trabalho objetiva analisar os sentidos atribuídos à leitura no discurso de alunos do $6^{\circ}$ ano de um Colégio Estadual na cidade de Guarapuava-PR, em 2013. A fundamentação teórica utilizada é a Análise de Discurso de orientação francesa, a partir dos postulados de Michel Pêcheux e EniOrlandi. Por meio de observações em sala de aula e de aplicação de questionários referentes ao ato de ler, a pesquisa torna-se relevante por apresentar possibilidades de análise sobre a linguagem, os sujeitos e a história, disseminando reflexões que provoquem outros olhares quanto ao imaginário de leitura que circula em sala de aula.
\end{abstract}

Palavras-chave: Leitura. Sujeitos alunos. Formações imaginárias. Efeitos de sentido.

Abstract: This work's main objective is to analyze the meaning assigned to the reading in the $6^{\text {th }}$ grade students from a state school in Guarapuava-PR, in 2013. The theoretical foundation used was the French oriented speech analyzes, from postulates of Michel Pêcheux and EniOrlandi. By classroom observation and by applying questionnaires about the reading act ,the research becomes relevant by showing language analyzes possibilities, the subjects and its history, disseminating reflections that can cause other views about the reading notions around the classroom.

Key-words:Reading, students subjects. Imaginary concepts.sense effects.

\section{Considerações iniciais}

A reflexão sobre a prática da leitura em sala de aula tem sido o alvo de inúmeros educadores e pesquisadores que se dedicam aos estudos da linguagem em diferentes níveis de ensino. Nesse contexto, nos deparamos com várias perspectivas teóricas que têm embasado as pesquisas sobre o ato de ler, dentro e fora do espaço escolar. Entre elas, recortamos a teoria da Análise de Discurso (AD) de orientação francesa, a qual teve seu início com os trabalhos de Michel Pêcheux,na França, e tem tido continuidade aqui no Brasil, a partir das pesquisas desenvolvidas por EniOrlandi e demais analistas que a ela se seguem.

Compreendida como uma "Teoria da Leitura" que busca responder, desde seu surgimento,“Como um texto significa?”, a AD busca compreender a língua fazendo sentido, partindo do trabalho social que constitui o homem e sua história. Nesses termos, a linguagem é concebida como mediadora entre o homem e a realidade natural e social em que está inserido.

${ }^{*}$ Ana Paula Kuchla, acadêmica do $2^{\circ}$ ano de Letras, da Universidade Estadual do Centro-Oeste - UNICENNTRRQ anapaulakuchla@gmail.com

${ }^{* *}$ Prof ${ }^{a}$ Dra. Luciana Fracasse, do Departamento de Letras, da Universidade Estadual do Centro-Oeste

UNICENTRO, Guarapuava-PR. 1fracasse@yahoo.com.br 
De acordo com Orlandi (2001a, p.9), a partir dos fundamentos da AD, podemos "problematizar as maneiras de ler, levar o sujeito falante ou o leitor a se colocarem questões sobre o que produzem e o que ouvem nas diferentes manifestações da linguagem". Nessa perspectiva, a autora afirma que, com a Análise de Discurso, busca-se entender como um objeto simbólico (enunciado, texto, pintura, música etc.) produz sentidos, o que consiste em mostrar os processos de significação instaurados no texto, permitindo a "escuta" de outros sentidos ali instaurados.

Norteados por essa postura teórica e motivados por gestos de leitura realizados ao longo de nosso percurso acadêmico, recortamos, como objeto de estudo, os enunciados produzidos por sujeitos alunos de $6^{\circ}$. Ano do Ensino Fundamental II. O recorte específico para o $6^{\circ}$. ano se justifica por ser este um período de transição, no qual os alunos deixam o Ensino Fundamental I ( $1^{\circ}$ ao $5^{\circ}$. Ano) e ingressam no Ensino Fundamental II ( $6^{\circ}$. ao $9^{\circ}$. Ano).

Assim sendo, nos empenhamos em analisar os sentidos atribuídos à leitura no discurso de alunos do $6^{\circ}$ ano do Ensino Fundamental II de um Colégio Estadual, na cidade de Guarapuava-PR ${ }^{1}$. Para viabilizarmos esse propósito, buscaremos, em específico, identificar as condições de produção nas quais a leitura é trabalhada em sala de aula; refletir sobre os sentidos atribuídos à leitura escolar nas últimas décadas; compreender as formações imaginárias que os sujeitos alunos possuem em relação à leitura; observar quais as regularidades constitutivas do/no discurso dos alunos sobre o ato de ler e os efeitos de sentido delas resultantes; e contribuir para a formação de um sujeito leitor que perceba a leitura como uma questão linguística, pedagógica e social ao mesmo tempo.

\section{Delineando o objeto de estudo}

Para a realização da pesquisa, inicialmente estabelecemos o contato com a Direção, a Equipe Pedagógica e a Professora Regente de Língua Portuguesa do $6^{\circ}$. Ano do Ensino Fundamental II, em um Colégio da rede pública de ensino, da cidade de Guarapuava. A escolha do colégio não foi por acaso, pois já o conhecia de um outro projeto que realizei no ano de $2012^{2}$. Foi a partir desse projeto, envolvendo a leitura,que passamos a nos interessar

${ }^{1}$ Para preservar a identidade do Colégio, não será exibido seu nome.

2 No ano de 2012 participamos do projetoextencionista "A promoção da Leitura Literária a partir da escola", tendo como coordenador o Prof ${ }^{\circ}$. Dr. Cláudio José de Almeida Mello, da Universidade Estadual do Centro-Oeste - UNICENTRO.
} 
pelo imaginário de leitura que as crianças possuem.Assim sendo, fizemos o acompanhamento das aulas de Língua Portuguesa, totalizando12horas em sala de aula, a partir de observações participativas, nas quais auxiliamos os alunos na realização das atividades durante as aulas. Em seguida, elaboramos um questionário, compartilhado com a Professora Regente, e distribuímos para todos os vinte e trêsalunos da turma. O questionário possui a seguinte estrutura, conforme podemos observar no quadro 1:

Quadro 1: Questionário norteador da pesquisa

1) Você tem acesso a quais tipos de leitura?

( ) jornais - com que frequência:__quais:

( ) revistas - com que frequência:__ quais:

( ) livros - com que freqüência_quais:

( ) histórias em quadrinhos: com que frequência:___quais:

( ) material publicitário: com que frequência:_quais:

( ) programas de TV: com que frequência:__quais:

( ) páginas da internet: com que frequência:__quais:

( ) rádio - com que frequência:__quais:

( ) outros: com que frequência: __ quais:

2) Sua família (pais, irmãos) tem ohábito de ler? Com que frequência?

3) Quando você começou a ler? De que forma isso ocorreu? Em casa? Na escola?

4) Para você, o que é a leitura?

5) Qual a importância que a leitura tem na sua vida?

6) O que você mais gosta de ler? Por quê?

7) O que você menos gosta de ler? Por quê?

8) Você lê frequentemente?

9) Como você tem acesso ao material de leitura? Você tem dificuldades?

10) Qual a importância das novas tecnologias (mensagem de celular, uso da internet, redes sociais) no seu dia-a-dia?

11) Qual importância da leitura no ambiente escolar? Você se sente motivado a ler mais sobre os assuntos depois das atividades trabalhadas em sala de aula?

12) Como uma boa leitura pode te ajudar em seu futuro (trabalho ou estudo)? Você já viveu alguma situação em que a leituramarcou a sua vida? Conte-nos.

Paralelamente à coleta dos dados, realizamos as leituras referentes à Análise de Discurso e ao percurso histórico que constitui o trabalho com a leitura no espaço escolar. A partir desse embasamento, analisaremos os discursos produzidos pelos sujeitos alunos, buscando identificar quais são as formações imaginárias que eles possuem no que se refere ao 
ato de ler.

\section{A "leitura" em diferentes perspectivas}

Aprática de leitura em sala de aula é debatida e investigada por muitos teóricos, assim como também é tema de muitos trabalhos acadêmicos. Fazendo uma breve retomada, desde os tempos do império, a leitura era destinada, somente para os reis, sacerdotes, nobres, conselheiros, escribas ${ }^{3}$.Posteriormente, houve a Inquisição da Igreja Católica que proibiu a leitura de certos livros considerados impuros. Em seguida, as mulheres estavam impedidas do ato de ler, pois, a sociedade machista temia que elas se apropriassem das histórias de ficção narradas no livro, e começassem a usufruirdelasna vida real.

Desde a antiguidade podemos observar como a leitura foi reprimida, por questões sociais, políticas e culturais. Isso pode ter acarretado o descaso com a leitura na atualidade? Se a trajetória da leitura fosse diferente, desde o seu início, ou seja, todos tivessem o direito e a oportunidade de ler, hoje seria diferente? Esses são questionamentos feitos quando queremos entender a concepção do que é ler para nossos alunos, ou quando queremos entender o "por que" de não gostarem dessa prática, que deveria ser diária e por prazer, sem ser por obrigação, a pedido dos professores, os quais são determinados, histórica e ideologicamente, como detentores do conhecimento, autoridades da sala de aula(FURLAN; MEGID, 2009, p.13).

Nos tempos primórdios, o que muitas vezes impedia essa prática, era o desconhecimento da linguagem, pois, nem toda a população era conhecedora do código escrito. E hoje o que impede os nossos filhos, alunos a lerem, se eles estão matriculados em escolas? Seria a tecnologia? A era da informatização? Segundo Ezequiel Theodoro da Silva, "no lar da grande maioria das crianças brasileiras, a televisão reina absoluta, muitas vezes dificultando possíveis aproximações com os livros"(SILVA, 1991, p.66). Outro fator seria a falta de incentivo dos pais, e até mesmo o não exemplo de leitores para seus filhos. As desculpas dadas pelos pais são a falta de tempo, a falta de vontade, e em alguns casos por serem analfabetos.

Segundo Menegassi (2010, p. 15), o conceito de leitura ao longo dos anos sofreu modificações. O primeiro conceito foi o de decodificação, ou seja, o leitor apenas

\footnotetext{
${ }^{3}$ Dados coletados da Dissertação de Mestrado de Lucas Macedo "Práticas de Leitura e Biblioteca no imaginário de adolescentes do Ensino Médio em Guarapuava-Pr”, Maringá, 2012.
} 
decodificava as palavras e produzia sentidos de acordo com o que o autor do texto pretendia. Um segundo conceito surge quando é levado em consideração o leitor, que, a partir de suas vivências, de suas experiências, construirá novos sentidos ao texto. O terceiro leva em consideração a interação entre texto e leitor, que tenta desvendar o porquê o autor diz o que diz. E o quarto conceito diz respeito à Análise de Discurso que enfatiza como o texto significa, fazendo com que o aluno pense na possibilidade de resignificar o texto. Autor e leitor inseridos em um contexto sócio-histórico-ideológico são produtores de sentidos, pois a cada nova leitura, em períodos diferentes, novos significados surgem num mesmo texto. Para Menegassi,

a maneira mais adequada de trabalho com a leitura com os alunos ainda é o ecletismo teórico, isto é, o aproveitamento das características dos conceitos de leitura que são úteis à situação em que o professor e alunos estão interagindo, para produzir-se sentidos, em função das leituras estabelecidas para o texto trabalhado (MENEGASSI, 2010, p. 34)

\section{Uma teoria de leitura: AD e suas contribuições}

ParaOrlandi“na Análise de Discurso, procura-se compreender a língua fazendo sentido, enquanto trabalho simbólico, parte do trabalho social geral, constitutivo do homem e da sua história"(ORLANDI, 2009, p. 15). O estudo realizado por essa disciplina não busca explicar o que o texto quer dizer e, sim o que ele significa. Então conforme a autora nos explica, precisamos trabalhar "a relação língua-discurso-ideologia. [...] Não há discurso sem sujeito e não há sujeito sem ideologia: o indivíduo é interpelado em sujeito pela ideologia e é assim que a língua faz sentido.”(ORLANDI, 2009, p. 17) Dessa forma, definimos o discurso, de acordo com a concepção de Orlandi como "efeito de sentidos entre locutores"(ORLANDI, 2009, p. 21).

$\mathrm{Na}$ concepção discursiva,segundoOrlandi, o professor tem papel de suma importância, pois proporciona "as condições de produção de leituras do aluno, dando oportunidade paraque ele construa sua história de leituras"(ORLANDI, 2008, p. 88). Assim, o sujeito leitor trará para sua leitura as suas experiências, tanto de vida,como de leituras anteriores, levando em conta que "a leitura é um dos elementos que constituem o processo de produção da escrita”.(ORLANDI, 2008, p. 90). Dessa forma, os sujeitos alunos precisam descobrir a valor da leitura, pois ela é essencial na vida de qualquer sujeito.

Nesse contexto,Hashigutinos traz a seguinte definição: "ler significa interpretar com 
bases em posições discursivas, isto é, um texto não contém, em si, sentido nenhum. Os sentidos são produzidos pelo trabalho do leitor com a memória discursiva na sua relação com as condições de produção"(HASHIGUTI, 2009, p. 28). Para AD, a escola tem a função "de formar sujeitos pelo discurso", assim como também a tarefa do professor

é justamente a de oferecer aos seus alunos elementos para que discutam as condições de produção dos diversos discursos, para que as questionem, de modo que os outros sentidos, também históricos, sejam evidenciados, e eles se desloquem e ocupem outra posição-sujeito. Para a $\mathrm{AD}$, o deslocamento está na possibilidade de produzir efeitos de sentido diferentes daqueles estabilizados em seu grupo social(BOLOGNINI, 2009, p.43-44).

Para Orlandi (2001, p.40), as condições de produção compreendem o que é material (a língua sujeita ao equívoco e à historicidade), o que é institucional (a formação social, em sua ordem) e o mecanismo imaginário. Segundo Pêcheux (1997, p.83-84), todo processo discursivo supõe a existência de formações imaginárias, as quais são designadas segundo um quadro como o seguinte:

Quadro 2:Formações Imaginárias

\begin{tabular}{|c|c|c|}
\hline $\begin{array}{l}\text { Expressão que designa as } \\
\text { formações imaginárias }\end{array}$ & Significação da expressão & $\begin{array}{l}\text { Questão implícita cuja } \\
\text { "resposta" } \\
\text { fubentende a } \\
\text { formação } \\
\text { correspondente }\end{array}$ \\
\hline & $\begin{array}{l}\text { Imagem do lugar de A para } \\
\text { o sujeito colocado em A }\end{array}$ & $\begin{array}{l}\text { "Quem sou eu para lhe } \\
\text { falar assim?" }\end{array}$ \\
\hline I A (B) & $\begin{array}{l}\text { Imagem do lugar de B para } \\
\text { o sujeito colocado em A }\end{array}$ & $\begin{array}{l}\text { "Quem é ele para que eu } \\
\text { lhe fale assim?" }\end{array}$ \\
\hline I B (B) & $\begin{array}{l}\text { Imagem do lugar de B para } \\
\text { o sujeito colocado em B }\end{array}$ & $\begin{array}{l}\text { "Quem sou eu para que ele } \\
\text { me fale assim?" }\end{array}$ \\
\hline I B (A) & $\begin{array}{l}\text { Imagem do lugar de A para } \\
\text { o sujeito colocado em B }\end{array}$ & $\begin{array}{l}\text { "Quem é ele para que me } \\
\text { fale assim"? }\end{array}$ \\
\hline I A (R) & $\begin{array}{l}\text { "Ponto de vista" de A sobre } \\
\text { R }\end{array}$ & "De que lhe falo assim?" \\
\hline I B (R) & $\begin{array}{l}\text { "Ponto de vista" de B sobre } \\
\text { R }\end{array}$ & $\begin{array}{l}\text { "De que ele me fala } \\
\text { assim?" }\end{array}$ \\
\hline
\end{tabular}

Fonte: PÊCHEUX (1997, p.83-84).

O autor (1997, p.83) afirma, a partir do quadro, que a posição dos protagonistas do discurso intervém a título de condições de produção e explica que o "referente" (R no quadro 
acima, corresponde ao contexto, à situação na qual aparece o discurso), pertence também às condições de produção. Pêcheux reitera que se trata de um objeto imaginário a saber, do ponto de vista do sujeito e não da realidade física.

Em nossa análise, temos como condições de produção, em sentido estrito, o discurso dos alunos do $6^{\circ}$ ano do Ensino Fundamental, de um Colégio público, situado no município de Guarapuava, Paraná, sobre o que é a leitura. E, em sentido amplo, temos o contexto sóciohistórico e ideológico que constitui o ambiente escolar brasileiro, contemplando as instâncias públicas e privadas do ensino.

Ao pensarmos nas formações imaginárias que regulam o discurso dos sujeitos alunos, compreendemos que a imagem de $\mathrm{A}$, refere-se, respectivamente à posição-sujeito aluno perante o ato de lerdesempenhado por ele [ I A (A)], a qual é apresentada ao sujeito leitorprofessor [ I A (B)], em condições de produção específicas que correspondem ao referente $(\mathrm{R})$ que corresponde à "leitura".

\section{O discurso dos alunos do Ensino Fundamental II: o que é a leitura?}

A disciplina de Língua Portuguesa é muito ampla para ser ensinada, pois abrange conteúdos de Análise Linguística, Produção Textual, Literatura e Leitura. Mas, com tanto conteúdo a ser trabalhado, sobra tempo para a leitura? Muitas vezes esse último tópico é deixado de lado, e com as tecnologias a todo vapor, muitos sujeitos se perguntam: ler pra quê? Se os jogos são mais divertidos e emocionantes. A leitura está perdendo seu espaço no público estudantil, e em geral, até os adultos dizem que não tem tempo para a leitura, imagina os adolescentes, que são impacientes. Fica a pergunta: por que os sujeitosalunos não gostam de ler? Quais os motivos? O que elesestão lendo?

Para tentarmos responder a esses questionamentos, analisaremos os discursos dos estudantesdo $6^{\circ}$, possibilitando, dessa forma, voz ao sujeito aluno, pois em muitos casos, quem responde esses questionamentos são os professores, “os alunos não gostam de ler, para eles é chato". Os educadores possuem essas respostas, mas e os alunos, o que eles falam? Será que é isso mesmo? O motivo de não gostarem da leitura varia, às vezes é atribuído a falhas do professor, desmotivação, pelo fato de serem alvo de humilhação, entre outros acontecimentos que os levam ao distanciamento perante o ato de ler. Com essa pesquisa, podemos observar o movimento transitório que ocorre entre um ciclo de ensino para outro (do $5^{\circ} \circ$ para $06^{\circ}$. Ano),com o intuito de verificarmos se há encantamento pela leitura; se esse encantamento 
permanece na mudança de ciclo ou se desaparece.

\subsection{Apresentação dos dados coletados}

Para realizar essa pesquisa aplicamos um questionário com doze questões, sendo uma objetiva e as demais descritivas, para vinte e três alunos. Algumas das questões serão aqui apresentadas com o auxílio de gráficos e as demais, devido às extensões variadas de resposta, serão expostas conforme a sequência da entrevista.

Gráfico 1: Relação de alunos pesquisados

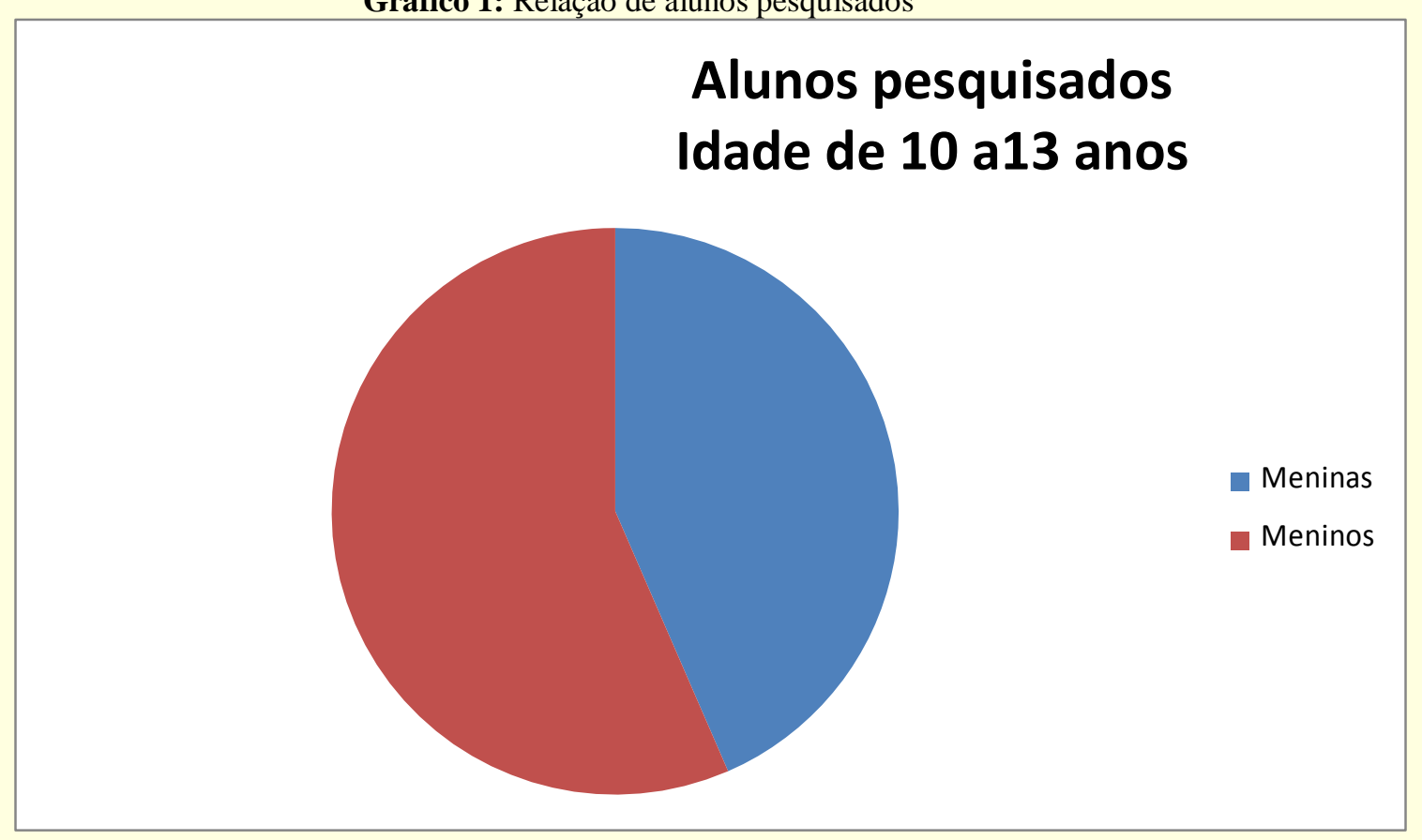

Eis as perguntas: 
Gráfico 2: Síntese dos tipos de leitura

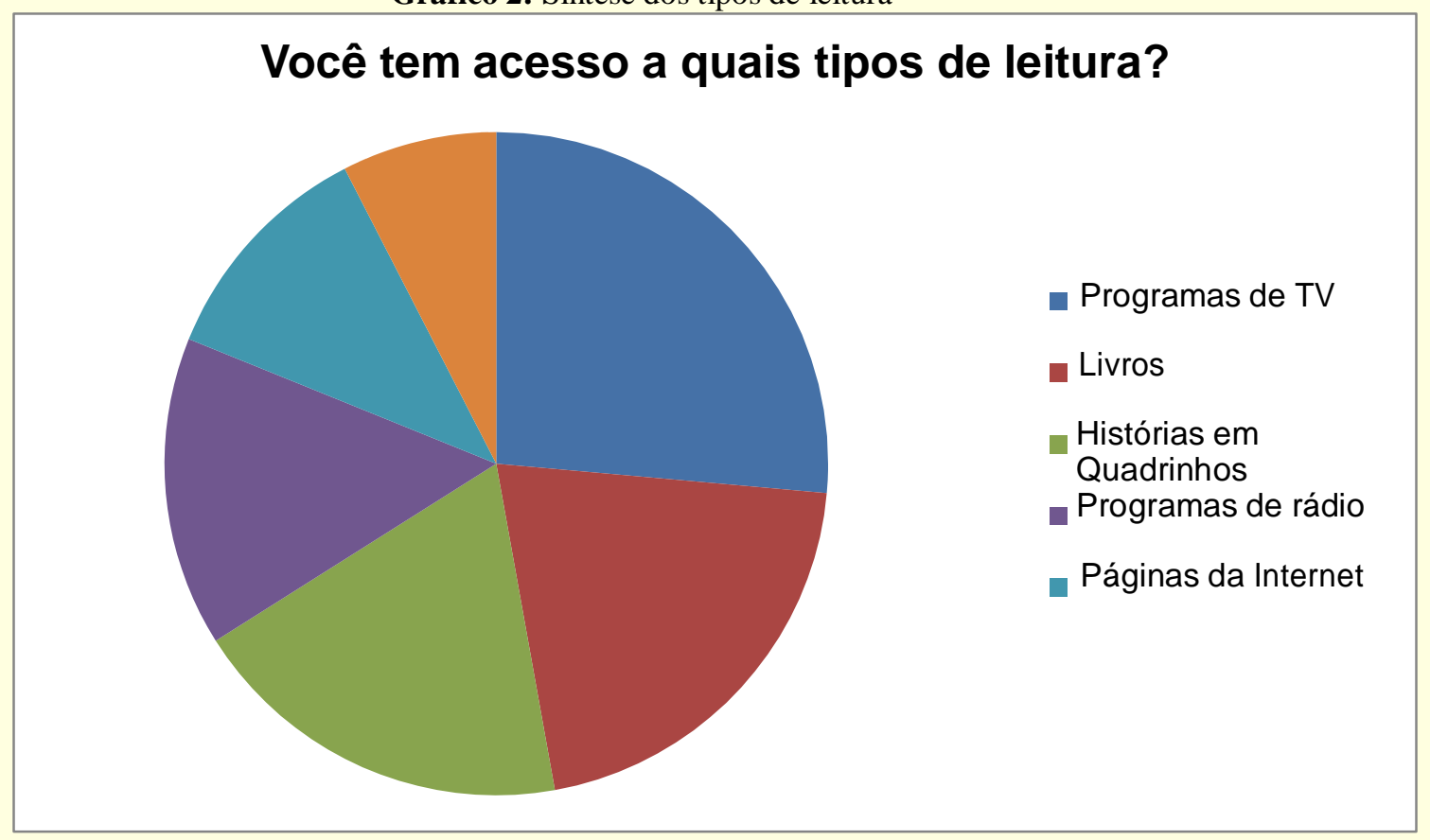

Quatorze alunos marcaram a opção programas de TV; onze alunos marcaram livros; dez alunos marcaram histórias em quadrinho; oito alunos marcaram programas de rádio; seis alunos marcaram páginas da internet; quatro alunos marcaram revistas; e dois alunos marcaram jornais, a opção que nenhum aluno marcou foi material publicitário.

Gráfico 3: Relação da família com a leitura

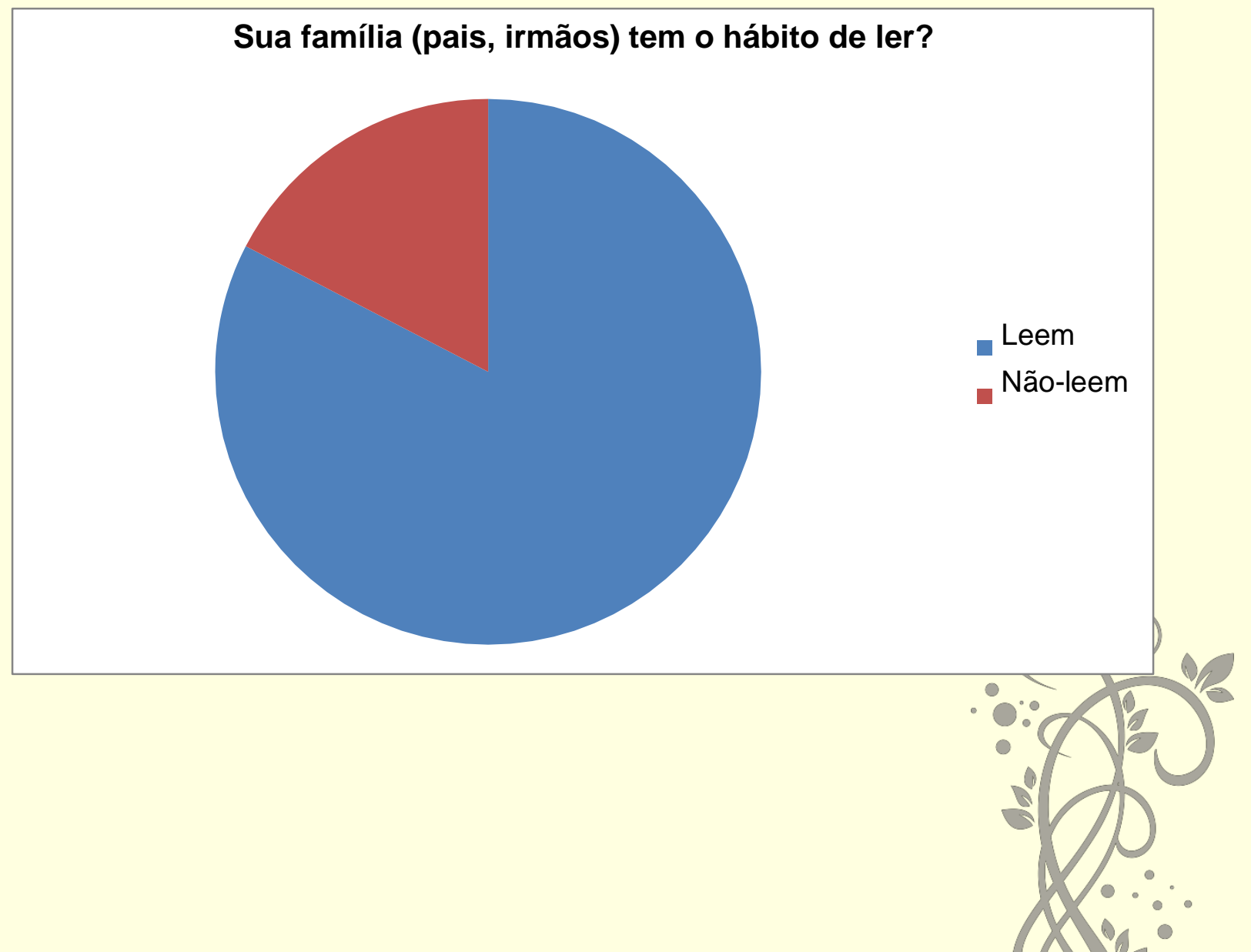


Gráfico 4: Pais e irmãos envolvidos com a leitura

\section{Sua família (pais, irmãos) tem o hábito de} ler?

Dezenove alunos responderam que seus familiares leem

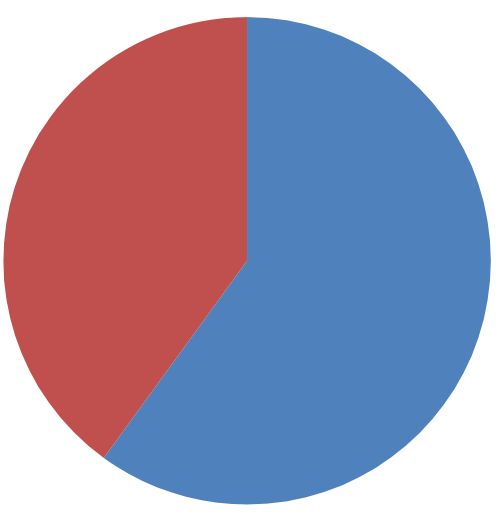

Gráfico 5: O contato inicial com a leitura

Quando você começou a ler? Em casa ou na escola?

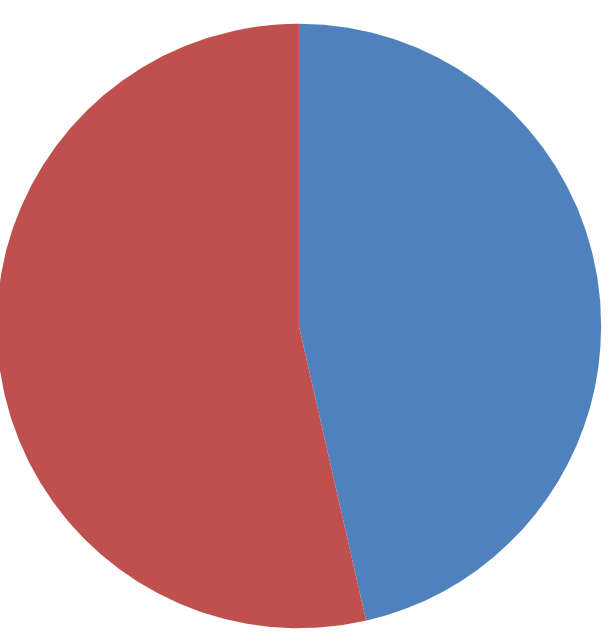




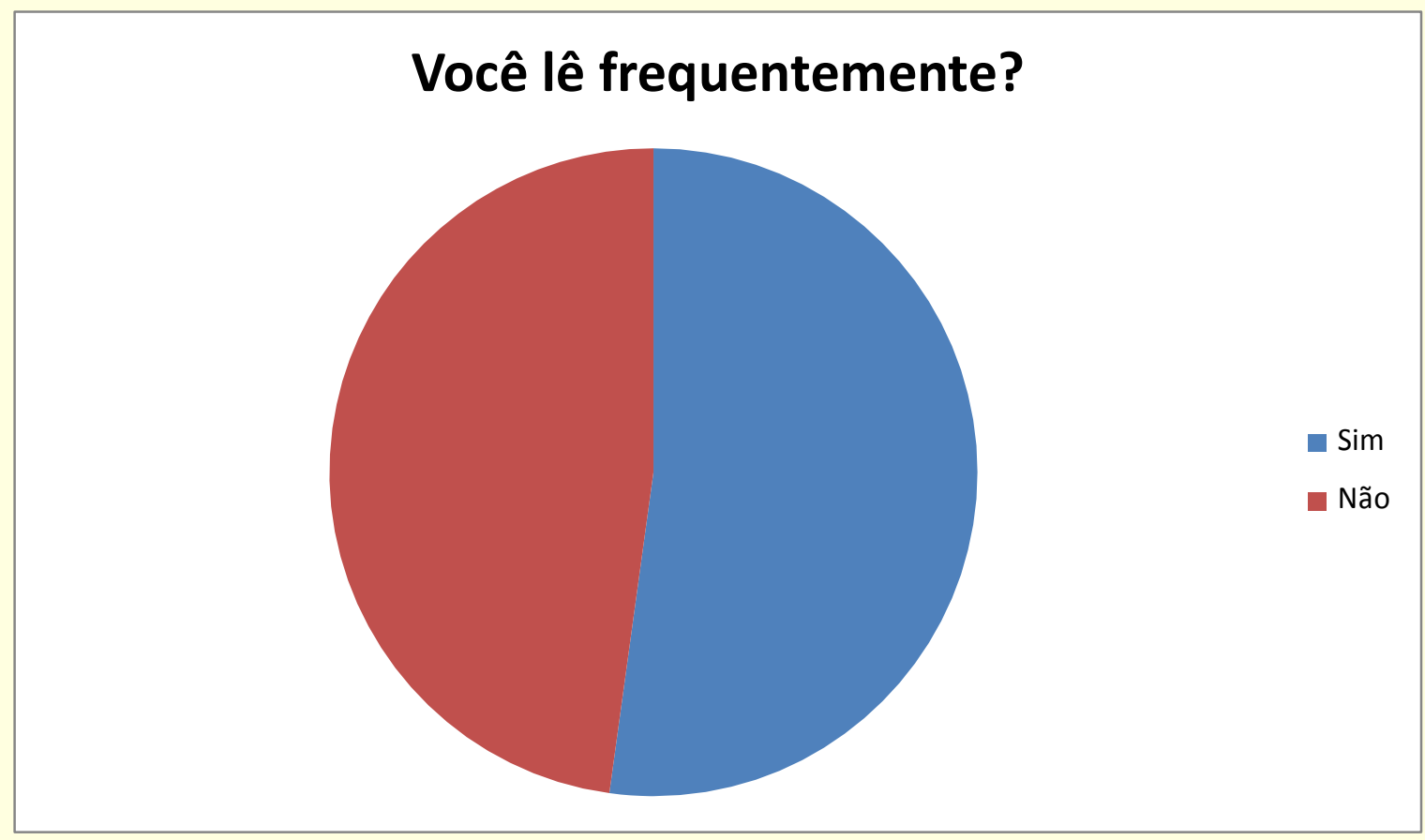

Essa questão varia muito, a idade em que começaram a ler vai de três anos até oito anos de idade. Treze alunos começaram a ler em casa e quinze alunos começaram a ler na escola.

4)Para você, o que é leitura?

O aluno $02^{4}$ : "é um momento de diversão".

O aluno 03: "a leitura é uma forma de aprendizado".

O aluno 10: "leitura para mim é uma forma de despertar a sua imaginação com os livros".

O aluno 12: "para mim a leitura é um habito muito bom que serve para melhorar o nosso portugues ao escrever, não só no escrever mas na fala também". ${ }^{5}$

O aluno 14: "é ler livro, é importante para o meu futuro". 6

O aluno 16: "saber o que está escrito",

O aluno 20: "a leitura é aprender novas palavras",

O aluno 21: "conhecer mundos diferentes".

O aluno 22: "silêncio, calma, concentração".

Ao refletirmos sobre as respostas dos sujeitos alunos, as palavras de Hashiguti (2009, p. 25) nos auxiliam na compreensão dos efeitos de sentido. Segundo a autora,

\footnotetext{
${ }^{4}$ Numeramos os questionários porque estamos preservando a identidade dos alunos.

${ }^{5}$ As respostas foram copiadas fielmente como os alunos escreveram, até mesmo com erros.

${ }^{6}$ Essa resposta foi dada por vários alunos.
} 
A escola, com sua metalinguagem, suas divisões, sua estruturação física, constrói toda uma memória de arquivo, que legitima, documenta e permite construir imaginários acerca de aprendizagem, leitura, conhecimento, professor e aluno, que circulam hoje em nossa sociedade e que estão presentes nos filmes, quadrinhos e em nossos dizeres. (HASHIGUTI, 2009, p. 25)

E é essa legitimação dos sentidos e saberes autorizados pela escola que sustenta os dizeres dos estudantes, uma vez que a escola também é responsável por inculcar formas específicas que garantam a estabilidade das relações de poder em uma sociedade (ALTHUSSER, 2001). Assim, nas respostas, ecoam as vozes dos sujeitos professores, em diferentes fases da vida escolar, as quais enfatizam, acima da diversão/prazer pela leitura, a importância de se adquirir algo novo, algo que falta aos alunos e que poderá ser conquistado por meio da leitura.

5)Qual a importância que a leitura tem na sua vida?

Muitos alunos elencaram a importância da leitura, entre as respostas produzidas destacamos:o aluno 04: “é muito importante por que as pessoas não ligam para livros e jornais só fazem leitura nas rede sociais e nos celulares"; o aluno 06: "ela me fez aprender várias coisas e para mim a leitura é o melhor aprendizado que tem"; o aluno 09: "arrumar um bom emprego"; oaluno 15 disse: "aprender mais" e oaluno 17: "melhor fazer os trabalhos escolares".

Ao afirmarem a relevância da leitura em suas vidas, os sujeitos alunos formulam discursos que retomam, em suas formações imaginárias, o discurso legitimado pela escola, no qual as relações sociais são bem definidas quanto aos sujeitos professores e alunos. Ou seja, é a falta constitutiva (aprender mais, arrumar um emprego etc.) que os alunos possuem que os motivam a querer ler, o que, nem sempre, é eficaz para que o ato de ler efetivamente aconteça em suas vidas.

6)O que você mais gosta de ler? Por quê?

Aluno 02:"livros de romance, escolares, de ação, de ciência";

Aluno 06: “eu gosto muito de ler histórias infantis e de quadrinhos por que assim eu ensino o meu irmão a ler";

Aluno 10: "eu gosto de ler historias, por quê incentiva a criatividade de fazer textos"; 
Aluno 14:"jornal";

Aluno 17: "filmes legendados", revistas;

Aluno 18: "histórias em quadrinhos";

Aluno 22: "gibi, letra de música".

7)O que você menos gosta de ler? Por quê?

Alguns alunos não gostam de ler. Aluno 04: "revistas, jornal”;aluno 20: "histórias de romance";aluno14: "livro com 300 paginas";aluno 03: "de ação", aluno 02: "comedia";aluno 17: "séries legendadas em inglês".

8)Você lê frequentemente?

As respostas foram diversas, predominando as seguintes informações:aluno 02: "a cada $2^{7}$ semanas;aluno 06: "quase todo dia", aluno 10: "uma vez por semana".

9)Como você tem acesso ao material de leitura? Você tem dificuldades?

Aluno 10: "Na escola, na biblioteca";aluno 02: "na casa";aluno 16: "sacolinha de leitura da escola" ; aluno 17: "tv, internet",aluno 05: "na casa da cultura", aluno 03: "livraria".

10) Qual a importância das novas tecnologias (mensagem de celular, uso da internet, redes sociais) no seu dia-a-dia?

Aluno 02: "ajudar em trabalhos da escola, avisar algo importante",

Aluno 12: "pesquisas escolares".

Aluno 05: "para ler livros virtuais".

Entre outras respostas o uso dessas tecnologias serve para:aluno 07: "acessar novidades"; aluno 16:“como forma de comunicação"; aluno 22: “ informação”.

11) Qual a importância da leitura no ambiente escola? Você se sente motivado a ler mais sobre os assuntos depois das atividades trabalhadas em sala de aula?

Aluno 12: "a importância da leitura no ambiente escolar é muito bom porque quando a gente lê errado corrige. Sim eu sinto motivado a ler sobre o assunto

\footnotetext{
${ }^{7}$ Ficaria mais propício escrever o número por extenso, porém o aluno colocou em algarismo.

${ }^{8}$ Essa sacola de leitura é um projeto da escola. Foram confeccionadas sacolas e cada uma possui livros, revistas, material diverso. Cada aluno leva essa sacola para sua casa e pode ficar com ela três dias. Dessa forma, os pais tem a oportunidade de ler.
} 
trabalhado em sala".

Aluno 02: "importante para entender melhor as atividades".

12)Como uma boa leitura pode te ajudar em seu futuro (trabalho ou estudo)? Você já viveu alguma situação em que a leitura marcou a sua vida? Conte-nos.

Aluno 09: "eu vou estudar para ser alguém no futuro".

Aluno 05: "Porque pode me dar um futuro melhor e um trabalho bom".

Aluno 12: "Pode sim no trabalho e no estudo. Sim eu já vivi uma situação em que

a leitura marcou minha vida. Eu tava lendo sobre profição e me interecei por engenheiro designer, que é o que quero ser".

Aluno 02: "sim vai me ajudar muito no meu futuro quando precisar ler discurso as tarefas da faculdade. A leitura vai ta sempre presente na minha vida”.

Aluno 15: "a gente pode ser escritora fazer bons livros".

Aluno 06: "pode ajudar para uma boa interpretação do conteúdo".

Aluno 03: "par um vestibular nos precisamos ler".

Aluno 10: "a leitura pode me ajudar muito na faculdade".

Aluno 07: "sim o dia que eu sempre erava"

Ao longo das respostas, somos desafiados a pensar, como nos diz Bolognini (2009, p.40), sobre a pergunta "para que ensinamos?", pois, embora compreendamos que o ato de ler nos acrescenta conhecimentos das mais variadas formas, observamos que as condições de produção da fala dos sujeitos alunos são, ideologicamente determinadas por discursos outros que se repetem ao longo dos tempos, mas que não provocam mudanças substanciais nas relações estabelecidas em sala de aula. Ou até pelo contrário, como identificamos na fala do aluno 07, a leitura funciona com o sentido de "apontar os erros" e isso passou a marcá-lo em sua caminhada escolar, reiterando a disposição dos papéis assumidos pelos professores, os que estão certos, e pelos alunos, os que estão errados, sem reflexões sobre os papéis de cada um.

\section{Considerações finais}

Dentre as respostas selecionadas, pudemos observar que vários fatores influenciam na realização do ato de ler, pois cada sujeito aluno possui a sua formação discursiva (FD), ou seja, "a FD é a matriz de sentidos que regula o que o sujeito pode e deve dizer e, também, o 
que não pode e não deve ser dito" (FERREIRA, 2001, p. 13) e esta encontra-se entrelaçada às formações imaginárias que os sujeitos alunos possuem. Nessa perspectiva, as respostas do questionário são perpassadas pelo funcionamento da ideologia, uma vez que ela é "entendida como efeito da relação entre sujeito e linguagem, (...) e está presente em toda manifestação do sujeito, permitindo sua identificação com a formação discursiva que o domina". (FERREIRA, 2001, p. 15).Dessa forma, o meio em que eles estão inseridos, determina o discurso.

Alguns sujeitos alunos reclamam da extensão dos livros e por isso têm dificuldade com a leitura, outros só conseguem ler quando estão em silêncio,alguns preferem ler em voz alta, porém isso se torna inviável no ambiente da sala de aula.Um aluno nos relatou, na última questão, sobre o fato da leitura ter marcado sua vida, que "foi o dia em que eu sempre errava", com certeza nesse dia, esse aluno foi muito humilhado, e jamais esquecerá esse momento. Cabe a nós professoresentender as dificuldades de cada aluno e ajudá-los para que superemsuas necessidades de aprendizagem, pois conforme nos afirma Bolognini

\begin{abstract}
Para a $\mathrm{AD}$, a escola está deslocada: enquanto para grande parte dos profissionais ela tem o papel de ensinar, para profissionais comprometidos com a $\mathrm{AD}$, antes de mais nada, ela forma sujeitos pelo seu discurso. [...] a tarefa do professor é justamente a de oferecer aos seus alunos elementos para que discutam as condições de produção dos diversos discursos, para que as questionem, de modo que outros sentidos, também históricos, sejam evidenciados, e eles se desloquem e ocupem outra posição-sujeito. Para a $\mathrm{AD}$, o deslocamento está na possibilidade de produzir efeitos de sentido diferentes daqueles estabilizados em seu grupo social(BOLOGNINI, 2009, p.43-44).
\end{abstract}

Assim sendo, entendemos que ao nos debruçarmos sobre os estudos da linguagem e a sua relação com a formação de professores, precisamos pensar o trabalho com a leitura numa perspectiva discursiva, pela qual o professor e o aluno seja compreendidos como posiçõessujeito "na relação com o trabalho de leitura no contexto escolar" (SILVA, 1991, p.31) e que a escola não funcione mais como uma prisão de sentidos (HASHIGUTI, 2009, p.27), na qual não se permite a possibilidade do deslize, do surgimento de outros sentidos possíveis, além dos já institucionalizados e autorizados, como pudemos ler nas respostas de muitos dos alunos participantes dessa

pesquisa.

\title{
6. Referências
}

ALTHUSSER, Louis. Aparelhos ideológicos de estado. 8 ed. Rio de Janeiro: Graal Ltda, 2001. 
BOLOGNINI, Carmem Zink. O desafio para o professor a exemplo do filme 200: uma odisseia no espaço. In: BOLOGNINI, Carmem Zink;PFEIFFER, Claudia; LAGAZZY, Suzy (orgs.). Discurso e ensino: práticas de linguagem na escola. Campinas, SP: Mercado das Letras, 2009. (Série Discurso e Ensino)

FERREIRA, Maria Cristina Leandro. (Orientadora); GODOY, Ana Boff de. [et al] (Bolsista de Iniciação Científica). Glossário de termos do discurso: projeto de pesquisa: a aventura do texto na perspectiva da teoria do discurso: a posição do leitor-autor (1997-2001). Porto Alegre: UFRGS. Instituto de Letras, 2001. 24 p.

FURLAN, Cássia Cristina; MEGID, Cristiane Maria. Língua e linguagem em movimento em sala de aula. In: BOLOGNINI, Carmem Zink;PFEIFFER, Claudia; LAGAZZY, Suzy (orgs.). Discurso e ensino: práticas de linguagem na escola. Campinas, SP: Mercado das Letras, 2009. (Série Discurso e Ensino)

HASHIGUTI, Simone T. Nas teias da leitura.In: BOLOGNINI, Carmem Zink; PFEIFFER, Claudia; LAGAZZY, Suzy (orgs.). Discurso e ensino: práticas de linguagem na escola. Campinas, SP: Mercado das Letras, 2009. (Série Discurso e Ensino)

MACEDO, Lucas. Práticas de leitura e biblioteca no imaginário de adolescente do Ensino Médio em Guarapuava - Pr. 2012. 84 fls. Dissertação (Mestrado em Letras - Estudos Literários) - Universidade Estadual de Maringá, Maringá, 2012.

MENEGASSI, Renilson José; ANGELO, Cristiane MalinoskiPianaro. Conceitos de Leitura. IN: MENEGASSI, Renilson José (orgs). Leitura e Ensino. 2. ed. Maringá: Eduem, 2010. p. 15-40. Formação de Professores - EAD; v.19.

ORLANDI, Eni. A linguagem e seu funcionamento: as formas do discurso. 5.ed. Campinas, SP: Pontes, 2009. 276p.

.Discurso e leitura. 8.ed. São Paulo: Cortez, 2008. 118p.

Análise de Discurso: princípios e procedimentos. Campinas: Pontes, 2001.

PÊCHEUX, Michel. Análise automática do discurso (AAD-69). Tradução de Eni P. Orlandi In: GADET, F; HAK, T. (org.) Por uma análise automatica do discurso: uma introdução à obra de Michel Pêcheux. Tradução de BethaniaS.Mariani, Eni P. Orlandiet al. 3.ed. Campinas, SP: Ed. da UNICAMP, 1997. p.61-161.

SILVA, Ezequiel Theodoro da.De olhos abertos: reflexões sobre o desenvolvimento da leitura no Brasil. São Paulo: Ática. 1991. 